\title{
Functionalized Dienes: A New Series of Potential Agents for the Treatment of Alzheimer's Disease
}

\author{
Aldo S. Oliveira, ${ }^{\oplus *, a}$ Lidiane Meier, ${ }^{a}$ Eduardo Zapp, ${ }^{a}$ Daniela Brondani, ${ }^{a}$ \\ Inês M. C. Brighente ${ }^{b}$ and Marcus M. Sá ${ }^{b}$ \\ ${ }^{a}$ Departamento de Ciências Exatas e Educação, Universidade Federal de Santa Catarina (UFSC), \\ 89036-004 Blumenau-SC, Brazil \\ ${ }^{b}$ Departamento de Química, Universidade Federal de Santa Catarina (UFSC), \\ 88040-900 Florianópolis-SC, Brazil
}

\begin{abstract}
We report a series of functionalized dienes as compounds of great potential in the treatment of Alzheimer's disease due to their antioxidant activity and ability to inhibit the enzyme acetylcholinesterase. The dienes tested showed high enzymatic inhibition capacity and accentuated antioxidant activity, which are comparable to or higher than the standards tested. Molecular docking studies were performed to confirm the experimental results. We also describe the correlation values between the antioxidant activity and oxidation potentials. Predicted bioactivity scores and quantum studies were also determined.
\end{abstract}

Keywords: dienes, antioxidant, acetylcholinesterase, Alzheimer's disease

\section{Introduction}

Alzheimer's disease (AD) is a neurological disorder that strongly impacts daily life and is characterized by successive cognitive losses. ${ }^{1} \mathrm{AD}$ is a disease that has been widely investigated in recent years, as it is one of the main diseases affecting the elderly over 65 years. ${ }^{2}$ Progressive memory loss and impairment in activities that use cognitive properties are frequent in patients suffering from Alzheimer's disease and denote a dramatic impairment in social relations. ${ }^{3}$ The great anatomo-physiological complexity of $\mathrm{AD}$, which involves many processes, implies the need to develop new therapies. ${ }^{4}$

Many scientific evidences obtained from the last decades have suggested that $\mathrm{AD}$ is a multifactorial disease. In addition to the low levels of acetylcholine, due to the activity of the enzyme acetylcholinesterase, Alzheimer's disease presents a set of characteristics, such as $\beta$-amyloid (A $\beta$ ) deposits, $\tau$-protein aggregation, oxidative stress, and dyshomeostasis of biometals. ${ }^{3}$

However, the best treatment currently available for $\mathrm{AD}$ is based on a cholinergic hypothesis, which relates the deficit of cognition to the reduction of the neurotransmitter acetylcholine $(\mathrm{ACh})$, that implies the reduction of the

*e-mail: aldo.sena@ufsc.br neurotransmission process. ${ }^{5,6}$ One of the enzymes involved in these biological processes is acetylcholinesterase (AChE), which is capable of regulating the process of neurotransmission and the levels of acetylcholine in the synaptic cleft, since it is able to catalyze the hydrolysis of this neurotransmitter. ${ }^{7}$ For this reason, many studies of theoretical and experimental nature have been developed with the purpose of finding compounds with ability to inhibit the enzyme acetylcholinesterase. ${ }^{6}$ Thus, the first drugs used for the symptomatic treatment of Alzheimer's disease act in a way to selectively inhibit AChE. In addition to tacrine (which is no longer used) and the potent nicotinic receptors rivastigmine and galantamine, the most prescribed drug donepezil has been widely used in the treatment of AD. Another commonly prescribed drug, especially in the eastern region, is huperzine $\mathrm{A}$, which is capable of inhibit $\mathrm{AChE}$ and presents an interesting association between antioxidant and anti-inflammatory action. ${ }^{8}$

Besides contributing to the treatment of $\mathrm{AD}$, antioxidant agents can increase the quality of life of the population by preventing or slowing the spread of degenerative diseases. In addition, they are of potential use to reduce costs related to public health care. ${ }^{8}$

The antioxidant potential of a drug is certainly one of the main parameters that are used for its biophysical characterization and it is very useful to anticipate its 
behavior in vivo. Thus, this parameter is of great importance to adequately measure the value of the dissociation constant of a therapeutically useful compound. ${ }^{9}$

1,3-Dienes comprise a distinct class of compounds in chemistry due to their valuable reactivity as synthetic building blocks as well as their unique electronic properties. They are structural frameworks of wide occurrence in biologically active natural products and pharmaceutically relevant agents. ${ }^{10,11}$ For these reasons, the stereoselective synthesis of dienes has been investigated over the years. Recently, we have reported the preparation of functionalized $(E, E)$-1,3-dienes $\mathbf{1}$ by reacting the corresponding allylic bromide $2^{12,13}$ with $\mathrm{PPh}_{3}$ in $\mathrm{CH}_{3} \mathrm{CN}$ at room temperature to give the allylic phosphonium salt $\mathbf{3}$, followed by the base-mediated Wittig reaction with aromatic aldehydes in aqueous medium under mild conditions (Scheme 1). ${ }^{14}$

Herein, we describe the antioxidant activity of a group of representative electron-deficient dienes. The AChE inhibition tests, the bioactivity score and the pharmacokinetics were also evaluated.

\section{Results and Discussion}

The antioxidant activity of the functionalized dienes $\mathbf{1}$ (Table 1) was analyzed by the following tests: iron chelating activity, reducing power, total antioxidant capacity, and cyclic voltammetry. The results are presented as mean \pm standard deviation ( $\mathrm{SD}, \mathrm{n}=3$ ).

The antioxidant activity of a compound can be measured by its ability to chelate metal ions, such as iron and copper. In this sense, chelating species can relate to existing oxidizing metals in living systems, in order to complex them. ${ }^{15}$ Iron(II) is distinguished in relation to its potent lipid peroxidation induction activity, and ferrozine can form complexes with $\mathrm{Fe}^{2+}$ in nearly quantitative yield. ${ }^{16}$ Remarkably, all the dienes tested demonstrated an ability to chelate $\mathrm{Fe}^{2+}$. Among the compounds analyzed, $\mathbf{1 b}$ and 1c proved to be the most potent chelators. It is important to highlight that the values found for the activity of the standards are compatible with those presented in the literature. ${ }^{16}$<smiles>[R]C=C(CBr)C(=O)OC</smiles>

\begin{tabular}{lcc}
\hline Diene & $\mathrm{R}$ & $\mathrm{R}^{1}$ \\
\hline 1a & $4-\mathrm{NO}_{2} \mathrm{C}_{6} \mathrm{H}_{4}$ & $2-\mathrm{NO}_{2} \mathrm{C}_{6} \mathrm{H}_{4}$ \\
1b & $4-\mathrm{NO}_{2} \mathrm{C}_{6} \mathrm{H}_{4}$ & $4-\mathrm{NO}_{2} \mathrm{C}_{6} \mathrm{H}_{4}$ \\
1c & $3-\mathrm{NO}_{2} \mathrm{C}_{6} \mathrm{H}_{4}$ & $4-\mathrm{NO}_{2} \mathrm{C}_{6} \mathrm{H}_{4}$ \\
1d & $2-\mathrm{ClC}_{6} \mathrm{H}_{4}$ & $2-\mathrm{NO}_{2} \mathrm{C}_{6} \mathrm{H}_{4}$ \\
1e & $3,4-\left(\mathrm{OCH}_{2} \mathrm{O}\right) \mathrm{C}_{6} \mathrm{H}_{3}$ & $3-\mathrm{NO}_{2} \mathrm{C}_{6} \mathrm{H}_{4}$ \\
1f & $3,4-\left(\mathrm{OCH}_{2} \mathrm{O}\right) \mathrm{C}_{6} \mathrm{H}_{3}$ & $2-\mathrm{NO}_{2} \mathrm{C}_{6} \mathrm{H}_{4}$ \\
\hline
\end{tabular}

Scheme 1. Synthesis of 1,3-dienes $\mathbf{1}$ from allylic phosphonium salts $\mathbf{3}$ through the Wittig reaction.

Table 1. Antioxidant activity of functionalized dienes 1a-f

\begin{tabular}{|c|c|c|c|c|}
\hline Compound & $\begin{array}{l}\text { Iron chelating activity }\left(\mathrm{EC}_{50}\right)^{\mathrm{a}} / \\
\qquad\left(\mu \mathrm{g} \mathrm{mL} \mathrm{mL}^{-1}\right)\end{array}$ & Reducing power $(\mathrm{RP})^{\mathrm{b}}$ & Total antioxidant capacity (TAC) & $\begin{array}{l}\text { Onset oxidation } \\
\text { potential }(\mathrm{OP})^{\mathrm{c}} / \mathrm{V}\end{array}$ \\
\hline $1 \mathbf{a}$ & $125.44 \pm 0.23$ & 12.18 & 3.31 & $1.411 \pm 0.015$ \\
\hline $\mathbf{1 b}$ & $147.80 \pm 0.42$ & 11.82 & 3.20 & $1.441 \pm 0.017$ \\
\hline 1c & $141.21 \pm 2.47$ & 11.85 & 3.22 & $1.430 \pm 0.013$ \\
\hline 1d & $115.18 \pm 0.32$ & 12.39 & 3.36 & $1.327 \pm 0.018$ \\
\hline 1e & $92.16 \pm 0.55$ & 14.93 & 4.06 & $1.045 \pm 0.021$ \\
\hline 1f & $85.34 \pm 0.29$ & 14.93 & 4.06 & $1.035 \pm 0.007$ \\
\hline Rutin & $42.45 \pm 0.16$ & 15.85 & 3.05 & $1.098 \pm 0.003$ \\
\hline BHT & $20.65 \pm 0.02$ & 5.79 & 1.93 & $0.753 \pm 0.009$ \\
\hline EDTA & $4.63 \pm 0.12$ & - & - & - \\
\hline
\end{tabular}

${ }^{\mathrm{a}} \mathrm{EC}_{50}$ value of iron(II) ions that were chelated by $50 \%$; ${ }^{\mathrm{b}} \mathrm{mol}$ of ascorbic acid / mol of compound. The number of mols of the compounds was standardized for better data comparison; 'results versus $\mathrm{Ag} / \mathrm{Ag}^{+}$. BHT: butylated hydroxytoluene; EDTA: ethylenediamine tetraacetic acid. 
The reductive ability of a species is usually associated with the presence of reductants, which are able to exert antioxidant activity by breaking the chain of free radicals. Reducers also have the ability to reduce the concentration of oxidized intermediates through lipid peroxidation, acting as primary and secondary antioxidants. The reductive power assay is able to measure the donation ability of species with antioxidant characteristics using the potassium ferricyanide reduction method. ${ }^{17}$ The dienes 1a-f analyzed showed excellent experimental values for reducing power (Table 1). The results are expressed as mol of compound per mol of ascorbic acid, calculated by relating the results of the antioxidant activity of the compounds and the ascorbic acid standard with their molar masses. The higher this ratio, the higher the antioxidant activity. It is important to note that the two compounds with greater reducing power (1f and 1e) present the piperonyl (3,4-methylenedioxyphenyl) ring structure.

The phosphomolybdenum method was used to evaluate the total antioxidant capacity of the compounds under analysis..$^{18}$ All the dienes investigated in this work presented good results for this test, with superior activity compared to the standards used (Table 1). The antioxidant activity, assessed by this method, followed the same order as the reducing power. Correlation values $\left(\mathrm{r}^{2}\right)$ between the trials were observed: iron chelating activity and total antioxidant capacity $\left(\mathrm{r}^{2}=8891 ; y=-58.28 x+323.90\right)$; reducing power and iron chelating $\left(\mathrm{r}^{2}=0.8879 ; y=-15.98 x+325.9\right)$; reducing power and total antioxidant capacity $\left(\mathrm{r}^{2}=0.9999\right.$; $y=0.2744 x-0.0367)$.

Preliminary electrochemical studies were carried out by cyclic voltammetry to provide evidence for the role of the substituents on the antioxidant activity. The experimental results indicate that the electron-acceptor or -donor character of each substituent is directly related to the greater or lesser ability for oxidation and reduction, due to changes in electron density in the $\pi$-conjugated system. The onset oxidation potentials have been used to compare the antioxidant strength of dienes, with the low oxidation potentials being associated with a greater facility of a given molecule for electron donation and, thus, for a high antioxidant capacity. ${ }^{19}$ The antioxidant activity assessed by this method followed the same order as the previous trials (Table 1), with excellent correlation values: iron chelating activity and onset oxidation potencial $\left(\mathrm{r}^{2}=0.9118\right.$, $y=126.70 x-44.56$ ); total antioxidant capacity and onset oxidation potential $\left(\mathrm{r}^{2}=0.8891, y=-58.28 x+323.90\right)$; reducing power and onset oxidation potential $\left(\mathrm{r}^{2}=0.8879\right.$, $y=-15.98 x+325.90$ ).

All dienes 1a-f studied were evaluated as AChE inhibitors. The enzymatic inhibition was measured using the method described by Canto et al. ${ }^{4}$ with modifications. The concentration of the tested compounds that inhibited substrate hydrolysis by $50 \%\left(\mathrm{IC}_{50}\right.$, Table 2$)$ was determined by plotting the inhibition percentage against the sample solution concentration. The functionalized dienes 1a-f showed a high percentage of inhibition of AChE, being as active as the galantamine used as standard $\left(\right.$ Remynil $^{\oplus}$, a drug used for the treatment of AD). Of the six dienes tested, three were more active than the standard, demonstrating the great potential of these compounds to inhibit AChE.

Table 2. AChE inhibitory activity for functionalized dienes 1a-f

\begin{tabular}{lc}
\hline Compound & $\mathrm{IC}_{50}{ }^{a} /\left(\mu \mathrm{mol} \mathrm{L}{ }^{-1}\right)$ \\
\hline 1a & $17.20 \pm 0.08$ \\
1b & $17.90 \pm 0.03$ \\
1c & $17.40 \pm 0.06$ \\
1d & $16.20 \pm 0.07$ \\
1e & $15.60 \pm 0.02$ \\
1f & $15.10 \pm 0.09$ \\
Galantamine & $17.10 \pm 0.08$ \\
\hline
\end{tabular}

${ }^{a}$ The assays were performed in triplicate and the value was obtained from the mean. $\mathrm{IC}_{50}$ : concentration of the tested compounds that inhibited substrate hydrolysis by $50 \%$.

To explain the observed values for the $\mathrm{IC}_{50}$ and to conduct an appropriate discussion of the structure-activity relationship, molecular docking studies were performed. In this study, four types of score functions were considered: CHEMPLP, GoldScore, ChemScore and Asp. The results obtained using the different punctuation functions showed a high index of correlation in both the punctuation sequence and the position of the ligands, as observed in Figure 1.

For purposes of objectivity and maintaining the scope of work, we select the GoldScore scoring function to analyze the structure-activity relationship (Table 3 ). It is possible to observe a good correlation, Adj.R-Square 0.97560 and $y=-6.2090 x+175.3000$ between the $\mathrm{IC}_{50}$ data for AChE and the scores for compounds 1a-f.

A structure-activity relationship (SAR) study was carried out with the inhibitors 1a-f by molecular docking simulations. Interestingly, the enzymatic cavity of the human acetylcholinesterase (AChE) structure (PDB ID $4 \mathrm{MOE}$ ) is occupied by diene $\mathbf{1}$. This enzymatic cavity is the same binding region of the co-crystalized ligand dihydrotransinone ${ }^{21}$ and contains numerous aromatic and hydrophobic side chains of amino acid residues. Figure 2 shows the molecular docking of dienes $\mathbf{1 a}$ and $\mathbf{1 b}$.

Both compounds interact with the TYR 341 residue, either by interaction with the nitro group in the case of compound 1a or by $\pi-\pi$ interaction in the case of 


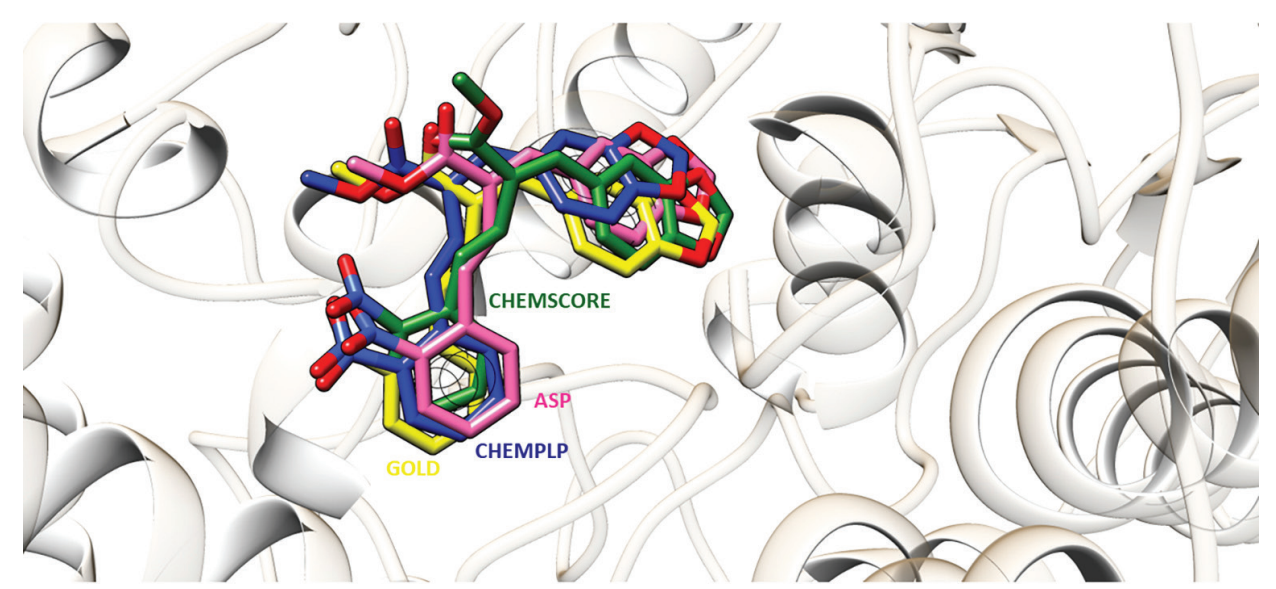

Figure 1. Overlap of molecular docking results for compound 1 f using different score functions in the Gold 5.6: CHEMPLP, GoldScore, ChemScore and ASP. The figure was elaborated in Chimera $1.13 .1 \mathrm{rc}^{20}$

Table 3. Comparison between the $\mathrm{IC}_{50}$ values of dienes 1a-f related to inhibition of AChE and the scores obtained through the Goldscore score function

\begin{tabular}{lcc}
\hline Diene & $\begin{array}{c}\mathrm{IC}_{50}-\text { inhibition of AChE / } \\
\left(\mu \mathrm{mol} \mathrm{L} \mathrm{L}^{-1}\right)\end{array}$ & Score \\
\hline 1a & $17.20 \pm 0.08$ & 67.309 \\
1b & $17.90 \pm 0.03$ & 65.366 \\
1c & $17.40 \pm 0.06$ & 67.124 \\
1d & $16.20 \pm 0.07$ & 73.338 \\
1e & $15.60 \pm 0.02$ & 78.864 \\
1f & $15.10 \pm 0.09$ & 82.128 \\
\hline
\end{tabular}

$\mathrm{IC}_{50}$ : concentration of the tested compounds that inhibited substrate hydrolysis by $50 \%$; AChE: acetylcholinesterase.

compound $\mathbf{1 b}$. This pattern of interaction is the same for compounds $\mathbf{1 c}$ and $\mathbf{1 d}$, which are shown in Figure 3.

It is interesting to note a correlation between the observed values for the $\mathrm{IC}_{50}$ of $\mathrm{AChE}$ and the number of interactions between the dienes and the residues at the catalytic site of the enzyme. Thus, the increase in activity is directly related to the increase in the number of bonds between the residues, as can be seen for compounds $1 e$ and $\mathbf{1 f}$ in Figure 4.

In addition to the TYR 341 residue, which interacted with all compounds of the tested series, the more active compound $1 \mathbf{f}$ showed two $\pi-\pi$ interactions with the TYR 72 residue, a $\pi-\pi$ interaction with TRP 286 and finally an interaction with the ARG 296 residue. These interactions agree with the scores and confirm the order of activity observed in the in vitro assay.

For the development of compounds with the desired therapeutic effect, administered orally, certain properties of the lead compound should be taken into consideration, such as Lipinski's five refrains, ${ }^{22}$ or the parameters adopted by Veber et al. $^{23}$ in order to enable better selection conditions for candidates for further development and to optimize drug production. In this sense, the molecular modeling provides subsidies in the context of bioinformatics and computer chemistry, allowing access to a large number of information about the compound quickly and safely, even in the physical absence of a particular compound. ${ }^{24}$

Besides the high activity, a lead candidate must have important pharmacokinetic properties in biological systems. The hydrophilic or lipophilic nature of the lead candidate affects drug absorption, bioavailability, metabolism, and drug-receptor interactions, as well as its toxicity. It is a complex equilibrium of various properties and structural characteristics of a compound. ${ }^{22}$
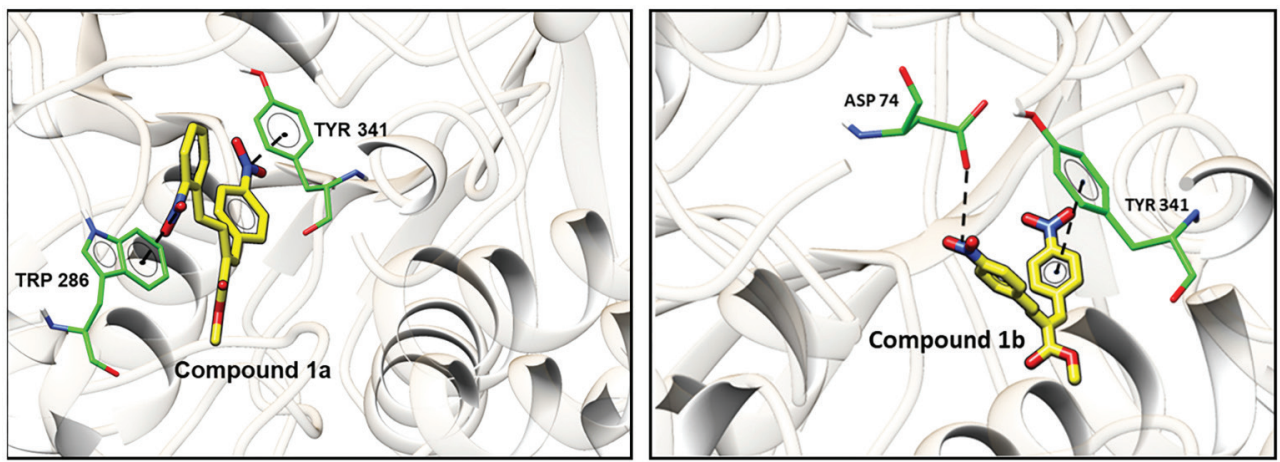

Figure 2. Intermolecular interactions of dienes $\mathbf{1 a}$ and $\mathbf{1 b}$ in the enzymatic cavity of the AChE enzyme. The figure was prepared using Chimera $1.13 .1 \mathrm{rc} .{ }^{20}$ 

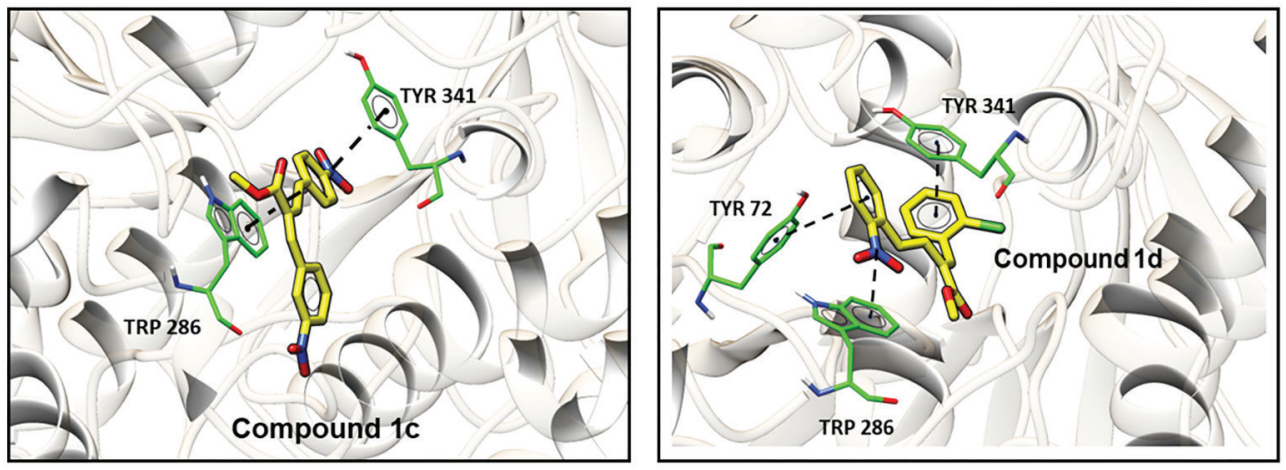

Figure 3. Intermolecular interactions of dienes $\mathbf{1} \mathbf{c}$ and $\mathbf{1 d}$ in the enzymatic cavity of the AChE enzyme. The figure was prepared using Chimera $1.13 .1 \mathrm{rc} .{ }^{20}$
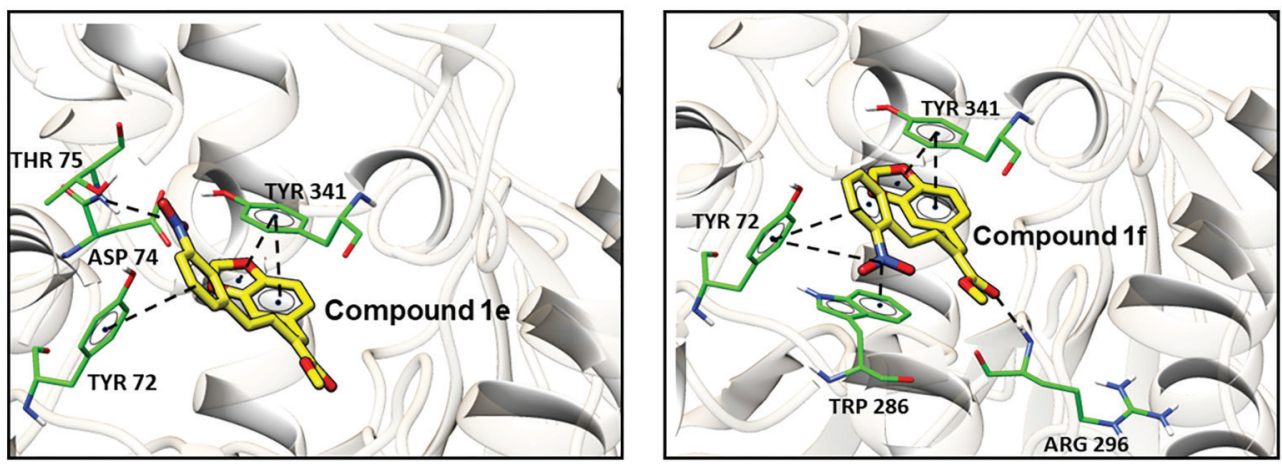

Figure 4. Intermolecular interactions of dienes $\mathbf{1 e}$ and $\mathbf{1}$ in the enzymatic cavity of the AChE enzyme. The figure was prepared using Chimera $1.13 .1 \mathrm{rc}{ }^{20}$

To access the pharmacokinetic profile, we employed the in silico tools Osiris, ${ }^{25}$ Petra, ${ }^{26}$ and Molinspiration, ${ }^{27}$ which have been validated with almost 7,000 drugs on the market. ${ }^{28}$ Data carried out for the functionalized dienes and standards using Molinspiration ${ }^{27}$ are presented in Table 4.

All functionalized dienes showed calculated octanol/ water partition coefficient (milogP) below 5. For all other parameters, data for dienes 1a-f are in complete accordance with the Lipinski's rules, i.e., molecular weight (MW) under 500; milogP less than 5; up to 5 hydrogen bond donors (nOHNH); less than 10 hydrogen bond acceptors (nON).
These desirable predicted properties reinforce the pharmacological potential of dienes 1a-f. As a rule, the larger the bioactivity score, the higher the probability that the investigated compound will be active. Therefore, a molecule having bioactivity score more than 0.00 is most likely to possess considerable biological activities, while values between -0.50 to 0.00 are expected to be moderately active. If score is less than -0.50 it is presumed to be inactive..$^{29}$ The predicted bioactivity scores of screened compounds as well as their comparison with the standard drugs for G-protein-coupled receptors (GPCRs) are summarized in Table 5. On average, all

Table 4. Parameters of molecular properties for functionalized dienes 1a-f and standards

\begin{tabular}{lccccccccc}
\hline Compound & miLogP & TPSA / $\AA^{2}$ & natoms & MW & nON & nOHNH & nviolations & nrotb & Volume / $\AA^{3}$ \\
\hline 1a & 4.50 & 117.95 & 26 & 354.32 & 8 & 0 & 0 & 7 & 301.48 \\
1b & 4.71 & 117.95 & 26 & 354.32 & 8 & 0 & 0 & 7 & 301.48 \\
1c & 4.71 & 117.95 & 26 & 354.32 & 8 & 0 & 0 & 7 & 301.48 \\
1d & 5.00 & 72.13 & 24 & 343.77 & 5 & 0 & 0 & 6 & 291.69 \\
1e & 4.64 & 90.60 & 26 & 353.33 & 7 & 0 & 0 & 6 & 302.08 \\
1f & 4.44 & 90.60 & 26 & 353.33 & 7 & 0 & 0 & 6 & 302.08 \\
Rutin & -0.77 & 249.20 & 42 & 594.52 & 15 & 9 & 3 & 6 & 488.05 \\
BHT & 5.43 & 20.23 & 16 & 220.36 & 1 & 1 & 1 & 2 & 241.00 \\
Galantamine & 1.54 & 41.93 & 21 & 287.36 & 4 & 1 & 0 & 1 & 268.19 \\
\hline
\end{tabular}

miLogP: calculated octanol/water partition coefficient; TPSA: topological polar surface area; natoms: number of atoms; MW: molecular weight; nON: hydrogen bond acceptors; nOHNH: hydrogen bond donors; nviolations: number of violations of the Lipinski's Rule; nrotb: number of rotatable bonds; BHT: butylated hydroxytoluene. 
Table 5. Bioactivity scores for functionalized dienes 1a-f and standards

\begin{tabular}{|c|c|c|c|c|c|c|}
\hline Compound & GPCR ligand & $\begin{array}{c}\text { Ion channel } \\
\text { modulator }\end{array}$ & Kinase inhibitor & $\begin{array}{c}\text { Nuclear receptor } \\
\text { ligand }\end{array}$ & Protease inhibitor & Enzyme inhibitor \\
\hline $1 \mathrm{a}$ & -0.26 & -0.19 & -0.48 & -0.01 & -0.39 & -0.19 \\
\hline $1 \mathrm{~b}$ & -0.23 & -0.18 & -0.40 & 0.01 & -0.27 & -0.15 \\
\hline $1 c$ & -0.23 & -0.18 & -0.40 & 0.01 & -0.27 & -0.15 \\
\hline 1d & -0.28 & -0.23 & -0.62 & 0.01 & -0.47 & -0.28 \\
\hline $1 e$ & -0.25 & -0.28 & -0.46 & -0.07 & -0.33 & -0.18 \\
\hline 1f & -0.24 & -0.28 & -0.52 & -0.07 & -0.43 & -0.21 \\
\hline Rutin & -0.02 & -0.46 & -0.11 & -0.23 & -0.08 & 0.15 \\
\hline BHT & -0.34 & 0.00 & -0.48 & -0.08 & -0.57 & -0.07 \\
\hline Galantamine & 0.93 & 0.26 & -0.15 & 0.20 & 0.01 & 1.02 \\
\hline
\end{tabular}

BHT: butylated hydroxytoluene.

dienes presented a good score, especially compounds $\mathbf{1 b}, \mathbf{1 c}$ and $1 \mathrm{~d}$.

Quantum chemistry studies were employed for dienes 1a-f. The $\mathrm{E}_{\text {номо }}$ (energy of the highest occupied molecular orbital) and $\mathrm{E}_{\mathrm{LUMO}}$ (energy of the lowest unoccupied molecular orbital) were determined using B3LYP theory level and 6-31G(d,p) basis function. The band gap (difference between HOMO and LUMO energies) was determined for all compounds (Table 6).

Table 6. Energy values of HOMO, LUMO and band gap of dienes 1a-f

\begin{tabular}{lccc}
\hline Compound & $\mathrm{E}_{\text {номо }} / \mathrm{eV}$ & $\mathrm{E}_{\mathrm{LUMO}} / \mathrm{eV}$ & Band gap $\left(\mathrm{E}_{\text {номо }}-\mathrm{E}_{\mathrm{LUMO}}\right) / \mathrm{eV}$ \\
\hline $\mathbf{1 a}$ & -7.37 & -3.21 & -4.17 \\
$\mathbf{1 b}$ & -7.30 & -3.24 & -4.06 \\
$\mathbf{1 c}$ & -7.30 & -3.22 & -4.08 \\
$\mathbf{1 d}$ & -7.18 & -2.96 & -4.22 \\
$\mathbf{1 e}$ & -6.45 & -2.59 & -3.86 \\
$\mathbf{1 f}$ & -6.55 & -2.38 & -4.16 \\
\hline
\end{tabular}

$\mathrm{E}_{\text {номо }}$ : energy of the highest occupied molecular orbital; $\mathrm{E}_{\mathrm{LuMO}}$ : energy of the lowest unoccupied molecular orbital; Band gap: difference between HOMO and LUMO energies.

The antioxidant activity of a substance is directly related to its electronic properties. The HOMO energy ( $\left.\mathrm{E}_{\text {номо }}\right)$ relates the molecule ability to donate electron density. In contrast, the LUMO energy $\left(\mathrm{E}_{\mathrm{LUMO}}\right)$ is associated with the ability to receive electrons. The interval between the two energy levels is the $\left(\mathrm{E}_{\mathrm{HOMO}}-\mathrm{E}_{\mathrm{LUMO}}\right)$ gap, which represents the reactivity of a chemical structure. The smaller the distance between the two energy levels, the more reactive the compound becomes. The HOMO and LUMO features of all dienes, with their respective energy values, are shown in Figure 5.

The HOMO profile, common for all structures, showed that the charge density is occupied in the region containing resonance features, such as the diene moiety and the 4-nitrophenyl group. The HOMO and LUMO energies remain almost unchanged for compounds $\mathbf{1 a}$ and $\mathbf{1 b}$. For the diene 1c, a substantially uniform contribution of the entire structure to the surface of the HOMO and the LUMO is observed. Diene 1d present significant differences in the molecular orbitals, possibly due to the presence of the chlorine atom in the benzene ring. The HOMO of structure $1 \mathbf{d}$ also tends to be distributed throughout the molecule. However, the LUMO tends to maintain the electron density close to the chlorine atom. The benzodioxolane group present in compounds 1e and $\mathbf{1 f}$ shows preference for the electronic density localization in the HOMO. However, in the LUMO of diene 1e, the charge density moves to the 3-nitrobenzene group, while for compound $\mathbf{1 f}$ the electronic density expands to 2-nitro and diene groups.

Figure 6 shows the HOMO and LUMO energy correlations with reducing power (RP), onset oxidation potential (OP), total antioxidant capacity (TAC) and $\mathrm{AChE}$ $\mathrm{IC}_{50}$. All experimental properties, i.e., $\mathrm{RP}, \mathrm{OP}, \mathrm{TAC}$ and $\mathrm{IC}_{50}$, were correlated with the HOMO and LUMO energies. In general, the results of the correlation coefficient $\left(\mathrm{r}^{2}\right)$ and Person's coefficient ( $r$ ) of these properties were better with HOMO energy than with LUMO energy.

By analyzing the data presented in Figure 6, it is possible to confirm that the experimental results obtained for the antioxidant activity correlated linearly with the energy of the HOMO and LUMO orbitals, with a minimum of $93.38 \%$ correlation. Therefore, the similarity among the coefficients $r$ and $r^{2}$ supports the conclusion that the antioxidant properties are directly related with $\mathrm{HOMO}$ and LUMO energies. LUMO energy was a better indicator than HOMO energy regarding acetylcholinesterase inhibitory activity, and these results are in accordance with recently published data. ${ }^{30}$ 

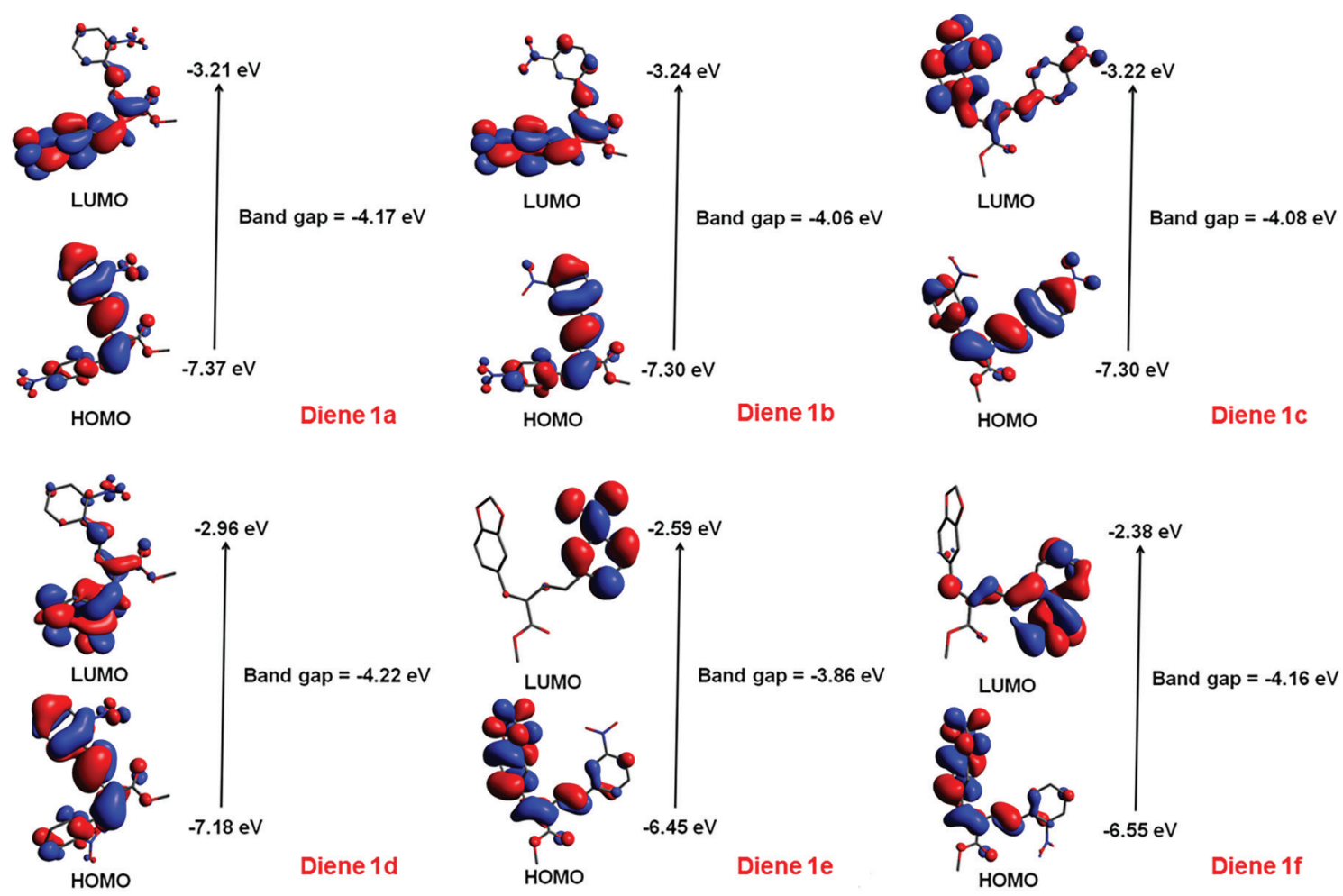

Figure 5. HOMO and LUMO energies for dienes 1a-f obtained by B3LYP theory level and 6-31G(d,p) basis function.

\section{Conclusions}

It can be concluded that functionalized dienes 1a-f are biologically important compounds that possess desirable molecular properties for drug likeness. The accumulation of data of this kind is expected to be useful for an improved understanding of the role and activity of dienes as potential candidates for the treatment of AD. Due to their ability to inhibit acetylcholinesterase and to act as antioxidant, functionalized dienes emerged as promising agents for the treatment of Alzheimer's disease. They also showed higher bioactivity score in comparison to standard drugs, besides a very favorable pharmacokinetic profile in compliance with Lipinski's rules. Further studies involving in vivo pharmacological trials are under development and their results will be published in the future.

\section{Experimental}

All reagents were obtained commercially (SigmaAldrich), and all solvents used were of analytical grade, without additional purification.

\section{Electrochemical assays}

Electrochemical measurements were performed with a Dropsens potentiostat (model $\mu$ Stat 400). Cyclic voltammetry experiments were performed on ca. $1.0 \mathrm{mmol} \mathrm{L}^{-1}$ of each compound in solutions of $0.1 \mathrm{~mol} \mathrm{~L}^{-1}$ tetra butyl ammonium hexafluorophosphate $\left(\mathrm{TBAPF}_{6}\right)$ in dry $\mathrm{CH}_{2} \mathrm{Cl}_{2}$ as the supporting electrolyte and the ferrocene/ ferricenium $\left(\mathrm{Fe} / \mathrm{Fe}^{+}\right)$redox couple as an internal reference. The experiments were performed utilizing a standard three-electrode cell with circular glassy carbon electrode, a Pt-wire counter electrode and an $\mathrm{Ag} / \mathrm{Ag}^{+}$as reference electrode. All measurements were conducted in electrolyte solution purged with purified nitrogen gas.

\section{Acetylcholinesterase inhibitory activity}

The enzymatic inhibition was measured using the method described by Canto et al..$^{4}$ with modifications. Briefly, $90 \mu \mathrm{L}$ of $50 \mathrm{mmol} \mathrm{L}^{-1}$ Tris-HCl buffer $\mathrm{pH} 8.0$, $30 \mu \mathrm{L}$ of a buffer solution containing the compound $\left(0.1 \mathrm{mg} \mathrm{mL}^{-1}\right)$ dissolved in $\mathrm{MeOH}$ and $15 \mu \mathrm{L}$ of an $\mathrm{AChE}$ solution containing $0.25 \mathrm{U} \mathrm{mL}^{-1}$, dissolved in $50 \mathrm{mmol} \mathrm{L}^{-1}$ Tris- $\mathrm{HCl} \mathrm{pH} 8$ buffer, containing $0.1 \%$ of bovine serum albumin were incubated for $15 \mathrm{~min}$. Then, $25 \mu \mathrm{L}$ of an acetylthiocholine iodide solution (15 mmol in water) and $140 \mu \mathrm{L}$ of Ellman's reagent $\left(3 \mathrm{mmol} \mathrm{L}^{-1}\right.$ in Tris- $\mathrm{HCl}$ $\mathrm{pH} 8.0$ buffer containing $0.1 \mathrm{~mol} \mathrm{~L}^{-1} \mathrm{NaCl}$ and $0.02 \mathrm{~mol} \mathrm{~L}^{-1}$ $\mathrm{MgCl}_{2}$ ) were added, and the final mixture was incubated for another $30 \mathrm{~min}$ at $28^{\circ} \mathrm{C}$. The absorbance of the mixture was measured at $405 \mathrm{~nm}$. The same solvent in which the 


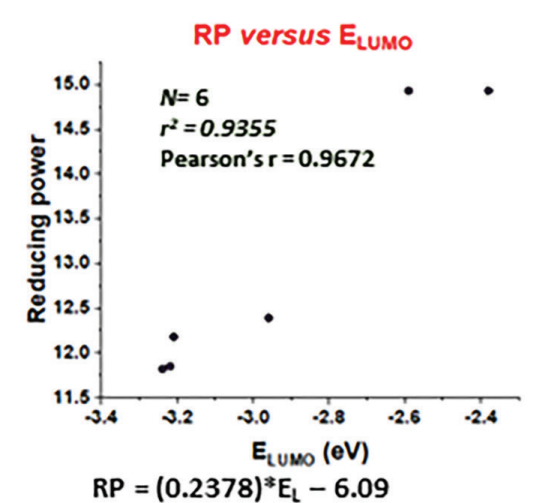

$R P=(0.2378)^{*} E_{L}-6.09$
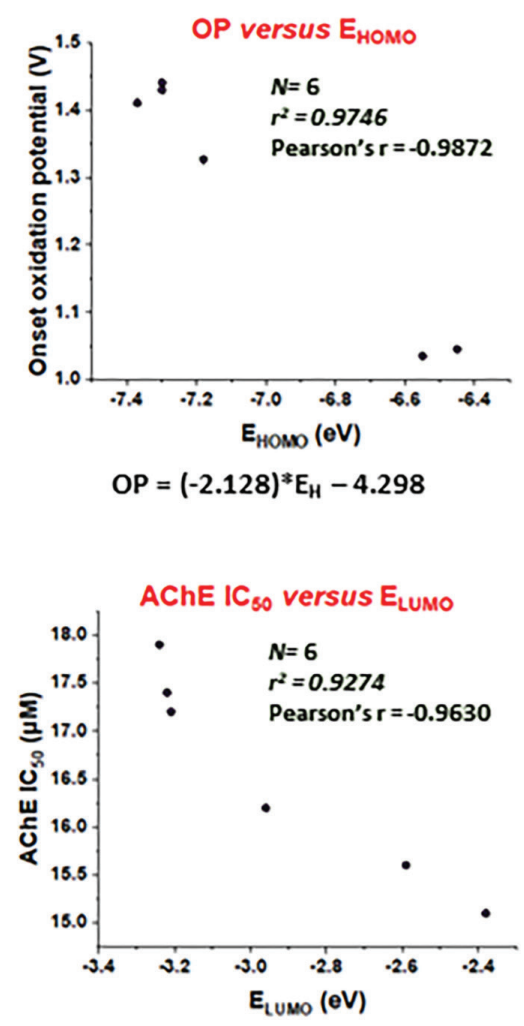

$A C h E=(-0.3211)^{*} E_{L}-2.386$

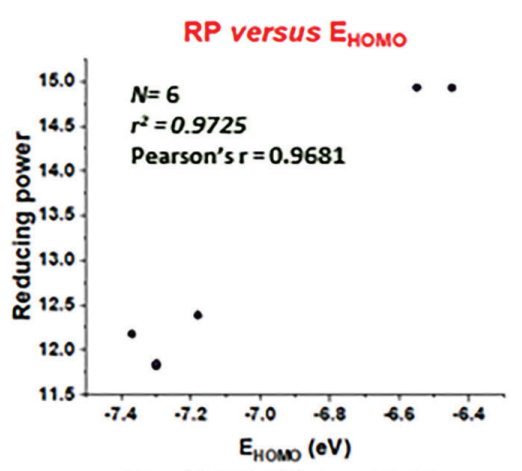

$R P=(0.2717)^{*} E_{H}-10.56$
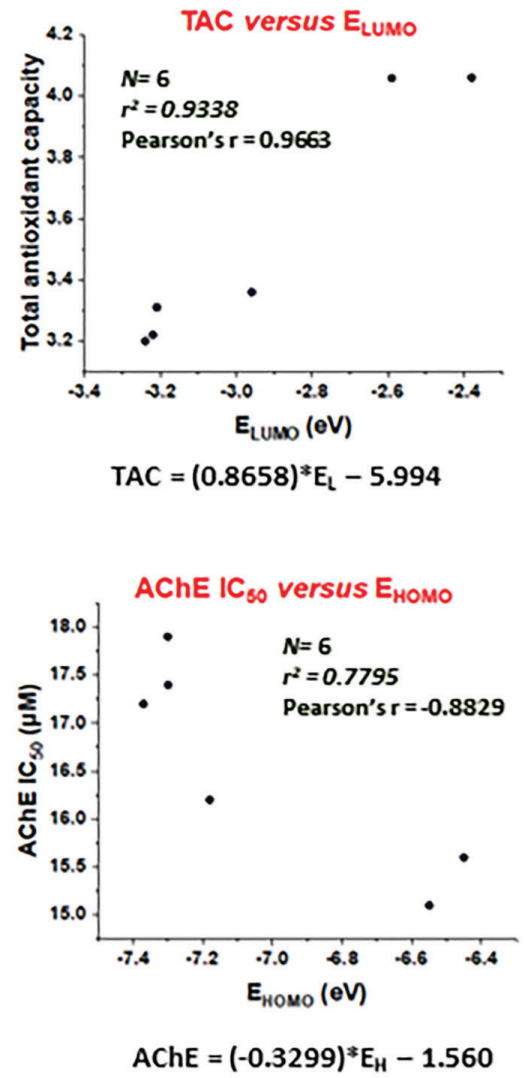
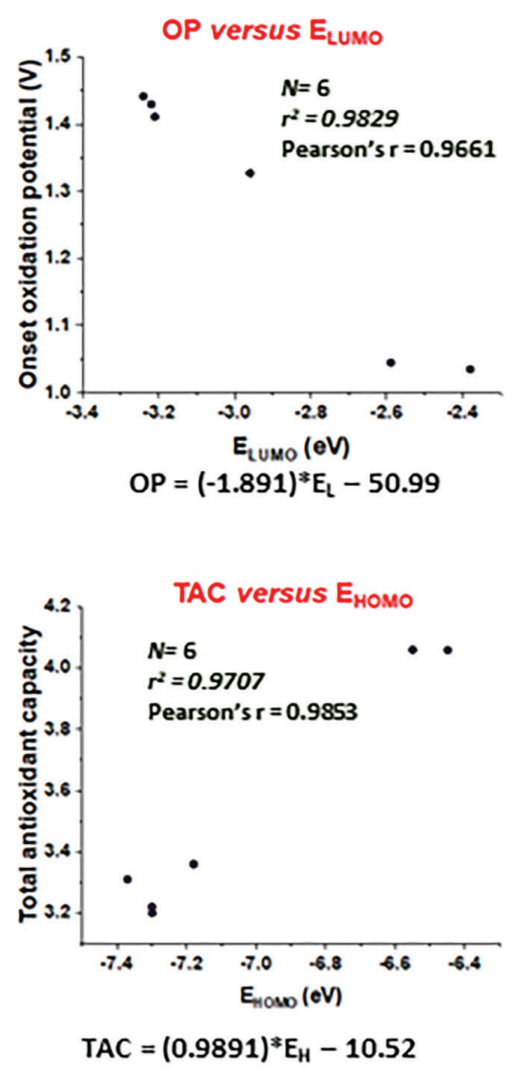

$O P=(-1.891)^{*} E_{L}-50.99$

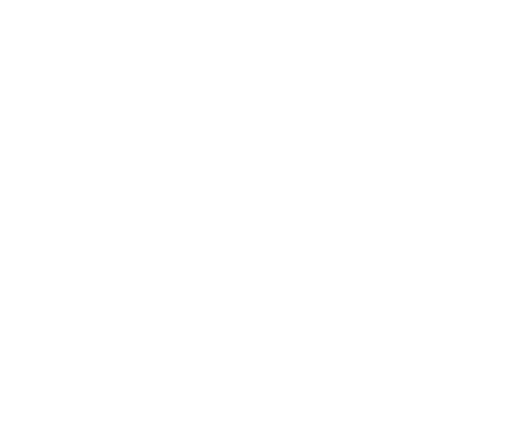

Figure 6. HOMO and LUMO energy correlations with reducing power (RP), onset oxidation potential (OP), total antioxidant capacity (TAC) and AChE IC ${ }_{50}$.

sample was dissolved, considered to have $100 \%$ AChE activity, was used as negative control. The inhibition (\%) was calculated following equation 1 , in which Asample is the absorbance of the sample and Acontrol is the absorbance without the sample:

I $(\%)=(100-$ Asample/Acontrol $) 100$

Total antioxidant capacity

Total antioxidant capacities of compounds were evaluated by phosphomolybdenum method. This assay is based on the reduction of $\mathrm{Mo}^{\mathrm{VI}}$ to $\mathrm{Mo}^{\mathrm{V}}$ by the antioxidant compounds and the subsequent formation of a green phosphate $/ \mathrm{Mo}^{\mathrm{V}}$ complex at acidic $\mathrm{pH}$ with a maximal absorption at $695 \mathrm{~nm} .^{31}$

Reduction power

$\mathrm{Fe}^{\mathrm{III}}$ reduction is often used as an indicator of electrondonating activity, which is an important mechanism of phenolic antioxidant action. ${ }^{32,33}$ The reducing power of compounds was determined according to the method of Yen and Chen. ${ }^{32}$ Different amounts of each compound 
(25-250 $\left.\mu \mathrm{g} \mathrm{mL}^{-1}\right)$ in methanol were mixed with phosphate buffer (2.5 mL, $0.2 \mathrm{~mol} \mathrm{~L}^{-1}, \mathrm{pH}$ 6.6) and potassium ferricyanide $\left[\mathrm{K}_{3} \mathrm{Fe}(\mathrm{CN})_{6}\right](2.5 \mathrm{~mL}, 1 \%)$. The mixture was incubated at $50{ }^{\circ} \mathrm{C}$ for $20 \mathrm{~min}$. A portion $(2.5 \mathrm{~mL})$ of trichloroacetic acid (10\%) was added to the mixture to stop the reaction, which was then centrifuged at $3000 \mathrm{rpm}$ for $10 \mathrm{~min}$. The upper layer of solution $(2.5 \mathrm{~mL})$ was mixed with distilled water $(2.5 \mathrm{~mL})$ and $\mathrm{FeCl}_{3}(0.5 \mathrm{~mL}, 0.1 \%)$, and the absorbance was measured at $700 \mathrm{~nm}$. Increased absorbance of the reaction mixture indicated increased reducing power.

Iron chelating activity

Solutions of compounds $(1 \mathrm{~mL})$ in different concentrations were evenly mixed with $0.05 \mathrm{~mL} \mathrm{FeCl}$ $\left(2 \mathrm{mmol} \mathrm{L}^{-1}\right)$, then it was added $0.2 \mathrm{~mL}$ of ferrozine solution $\left(5 \mathrm{mmol} \mathrm{L}^{-1}\right)$. The mixtures were shaken and left standing at room temperature for $20 \mathrm{~min}$, the absorbance values (Asample) of the mixtures were measured at $562 \mathrm{~nm}$. Methanol was used instead of the sample solution as blank control (Ablank) and $\mathrm{Na}_{2}$ EDTA was used as positive control (equation 2). ${ }^{4}$

$\mathrm{Fe}^{2+}$ chelating rate $(\%)=100[($ Ablank - Asample $) /$ Ablank $]$

Molecular docking and quantum studies

\section{Structure preparation}

All structures were built in the Avogadro program. ${ }^{34}$ The compounds were prepared at $\mathrm{pH} 8.0$, simulating the experimental conditions in the human ACE enzyme (ACEh). Subsequently, all structures were minimized using the universal force field (UFF) through the conjugate gradient algorithm.

\section{Preparation of human AChE}

The enzyme AChE (PDB ID 4M0E, ${ }^{21}$ resolution $1.95 \AA$ ) was selected from the protein database. The selection was based in the top resolution. The protein preparation was carried out in the Chimera 1.13 program. ${ }^{20}$ The chain B and EDO were eliminated. To predict the protonation states of the side chains of the amino acid at $\mathrm{pH}$ 8.0, the Jensen and co-workers ${ }^{35}$ method was applied in the protein. Next, the Dock Prep module was used for addition of hydrogen atoms, for deletion of crystallographic waters, and to add incomplete side chains through the Dunbrack 2010 rotamers library. ${ }^{35}$ The charge assignment was based on Gasteiger and Marsili ${ }^{36}$ model and in the standard residues through the AMBER ff14SB force field. ${ }^{37}$

\section{Molecular docking}

All structures were docked through the program GOLD 5.6 (Cambridge Crystallographic Center, Cambridge) software. ${ }^{38}$ The docking method used the genetic algorithm to generate the conformations of the poses at the binding site, changing the angles of the molecule. ${ }^{38}$ Afterward, the structure orientations were evaluated by fitness or score function. ${ }^{38}$ Next, the centroid of the co-crystallized compound was defined as sphere center of radius $6 \AA$. The ligands were submitted to parameters of the genetic algorithm, such as population size, selection pressure, operation numbers, island numbers, niche size, crossing frequencies and migration frequency of 100, 1.1, 100,000, 5, 2, 95 and 10 , respectively. The fitness function used to evaluate the poses of the conformations was based on force field, the GoldScore. The top conformation was considered with high score value and it was used in the structure-activity relationship studies.

\section{Density functional theory - geometry optimization}

All the energies of the HOMO and LUMO and geometry optimizations presented in this study were computed using the $\mathrm{B}^{2} \mathrm{LYP}^{39}$ hybrid density functional method implemented code package of the GAMESS (General Atomic and Molecular Electronic Structure System) program..$^{40}$ In these calculations $6-31 \mathrm{G}(\mathrm{d}, \mathrm{p}) 41$ basis function at the gas phase was considered and all molecules were considered singlet and neutral. In the calculations, the grid method and the correlations to Slater exchange potential were considered. Next, the Hückel method $^{42}$ generated an initial guess to the molecular orbitals and electron density. Subsequently, the selfconsistent field (SCF) convergence type was assigned through the restricted Hartree-Fock (RHF) ${ }^{43}$ algorithm, in which the SCF was limited until 48 iteration cycles. Furthermore, the geometry optimization was carried out by the quadratic approximation and the convergence of the gradient was considered of $0.0001 \mathrm{kcal} \mathrm{mol}^{-1}$. Afterward, the HOMO and LUMO energies were obtained and compared with the $\mathrm{IC}_{50}$ data (assay in vitro in $\mathrm{ACEh}$ ), the reducing power (RP), and the total antioxidant capacity (TAC) of the molecules. Finally, a quantitative propertyactivity relationship study was carried out through the correlations of the HOMO and LUMO energies with TAC, $\mathrm{RP}$ and $\mathrm{IC}_{50}$, by the least square method.

\section{Supplementary Information}

Supplementary data are available free of charge at http://jbcs.sbq.org.br as PDF file. 


\section{Acknowledgments}

The authors wish to thank the Central Analysis (Department of Chemistry, UFSC) for spectroscopic analysis, and FAPESC (Foundation for Research and Innovation Support of Santa Catarina) for financial support. M. M. S. is grateful to CNPq for a research fellowship.

\section{References}

1. Chauhan, K.; Datta, A.; Adhikari, A.; Chuttani, K.; Singh, A. K.; Mishra, A. K.; Org. Biomol. Chem. 2014, 12, 7328.

2. de Paula, A. A. N.; Martins, J. B. L.; Gargano, R.; dos Santos, M. L.; Romeiro, L. A. S.; Chem. Phys. Lett. 2007, 446, 304.

3. Mao, F.; Yan, J.; Li, J.; Jia, X.; Miao, H.; Sun, Y.; Huang, L.; Li, X.; Org. Biomol. Chem. 2014, 12, 5936.

4. Canto, R. F. S.; Barbosa, F. A. R.; Nascimento, V.; de Oliveira, A. S.; Brighente, I. M. C.; Braga, A. L.; Org. Biomol. Chem. 2014, 12, 3470.

5. de Paula, A. A. N.; Martins, J. B. L.; dos Santos, M. L.; Nascente, L. C.; Romeiro, L. A. S.; Areas, T. F. M. A.; Vieira, K. S. T.; Gambôa, N. F.; Castro, N. G.; Gargano, R.; Eur. J. Med. Chem. 2009, 44, 3754.

6. Nascimento, É. C. M.; Martins, J. B. L.; dos Santos, M. L.; Gargano, R.; Chem. Phys. Lett. 2008, 458, 285.

7. Yamazaki, D. A. S.; Cândido, A. A.; Bagatin, M. C.; Machinski Jr., M.; Mossini, S. A. G.; Pontes, R. M.; Rosa, F. A.; Basso, E. A.; Gauze, G. F.; J. Braz. Chem. Soc. 2016, 27, 1616.

8. Torres, F. C.; Gonçalves, G. A.; Vanzolini, K. L.; Merlo, A. A.; Gauer, B.; Holzschuh, M.; Andrade, S.; Piedade, M.; Garcia, S. C.; Carvalho, I.; von Poser, G. L.; Kawano, D. F.; Eifler-Lima, V. L.; Cass, Q. B.; J. Braz. Chem. Soc. 2016, 27, 1541.

9. Daldal, Y. D.; Demiralay, E. Ç.; Ozkan, S. A.; J. Braz. Chem. Soc. 2016, 27, 493.

10. Orimoto, K.; Oyama, H.; Namera, Y.; Niwa, T.; Nakada, M.; Org. Lett. 2013, 15, 768.

11. Laplace, D. R.; Verbraeken, B.; Hecke, K. V.; Winne, J. M.; Chem. - Eur. J. 2014, 20, 253.

12. Ferreira, M.; Fernandes, L.; Sá, M. M.; J. Braz. Chem. Soc. 2009, 20, 564.

13. Sá, M. M.; Ramos, M. D.; Fernandes, L.; Tetrahedron 2006, $62,11652$.

14. Sá, M. M.; Meier, L.; Heteroat. Chem. 2013, 24, 384.

15. Sowndhararajan, K.; Kang, S. C.; Saudi J. Biol. Sci. 2013, 20, 319.

16. Costa, T. G.; Feldhaus, M. J.; Vilhena, F. S.; Heller, M.; Micke, G. A.; Oliveira, A. S.; Brighente, I. M. C.; Monteiro, F. B. F.; Creczynski-Pasa, T. B.; Szpoganicz, B.; J. Braz. Chem. Soc. 2015, 26, 273.

17. Kowalewska, E.; Litwinienko, G.; Postepy Biochem. 2010, 53, 274.
18. Kumar, S.; Sandhir, R.; Ojha, S.; BMC Res. Notes 2014, 7, 560.

19. Arteaga, J. F.; Ruiz-Montoya, M.; Palma, A.; Alonso-Garrido, G.; Pintado, S.; Rodríguez-Mellad, J. M.; Molecules 2012, 17, 5126.

20. Pettersen, E. F.; Goddard, T. D.; Huang, C. C.; Couch, G. S.; Greenblatt, D. M.; Meng, E. C.; Ferrin, T. E.; J. Comput. Chem. 2004, 25, 1605.

21. Cheung, J.; Gary, E. N.; Shiomi, K.; Rosenberry, T. L.; ACS Med. Chem. Lett. 2013, 4, 1091.

22. Lipinski, C. A.; Lombardo, F.; Dominy, B. W.; Feeney, P. J.; Adv. Drug Delivery Rev. 1997, 23, 3.

23. Veber, D. F.; Johnson, S. R.; Cheng, H.-Y.; Smith, B. R.; Ward, K. W.; Kopple, K. D.; J. Med. Chem. 2002, 45, 2615.

24. Venkatesh, S.; Lipper, R. A.; J. Pharm. Sci. 2000, 89, 145.

25. https://www.organic-chemistry.org/prog/peo/, accessed in December 2018.

26. http://www2.chemie.uni-erlangen.de/software/petra/, accessed in December 2018.

27. https://www.molinspiration.com/services/, accessed in December 2018.

28. Messali, M.; Aouad, M. R.; Ali, A. A.-S.; Rezki, N.; Ben Hadda, T.; Hammouti, B.; Med. Chem. Res. 2015, 24, 1387.

29. Verma, A.; Asian Pac. J. Trop. Biomed. 2012, 2, S1735.

30. Sens, L.; de Oliveira, A. S.; Mascarello, A.; Brighente, I. M. C.; Yunes, R. A.; Nunes, R. J.; J. Braz. Chem. Soc. 2018, 29, 343.

31. Prieto, P.; Pineda, M.; Aguilar, M.; Anal. Biochem. 1999, 341, 337.

32. Yen, G.-C.; Chen, H.-Y.; J. Agric. Food Chem. 1995, 43, 27.

33. Ebrahimzadeh, A. M.; Nabavi, S. M.; Nabavi, S. F.; Bahramian, F.; Bekhradnia, A. R.; Pak. J. Pharm. Sci. 2010, 23, 29.

34. https://avogadro.cc/, accessed in December 2018.

35. Rostkowski, M.; Olsson, M. H.; Søndergaard, C. R.; Jensen, J. H.; BMC Struct. Biol. 2011, 11, 6.

36. Gasteiger, J.; Marsili, M.; Tetrahedron 1980, 36, 3219.

37. Maier, J. A.; Martinez, C.; Kasavajhala, K.; Wickstrom, L.; Hauser, K. E.; Simmerling, C.; J. Chem. Theory Comput. 2015, 11, 3696.

38. Verdonk, M. L.; Cole, J. C.; Hartshorn, M. J.; Murray, C. W.; Taylor, R. D.; Proteins: Struct., Funct., Genet. 2003, 52, 609.

39. Stephens, P. J.; Devlin, F. J.; Chabalowski, C. F.; Frisch, M. J.; J. Phys. Chem. 1994, 98, 11623.

40. Windus, T. L.; Schmidt, M. W.; Gordon, M. S.; ACS Symposium Series, vol. 592; Mattson, T. G., ed.; American Chemical Society: Washington, DC, USA, 1995, p. 16.

41. Ditchfield, R.; Hehre, W. J.; Pople, J. A.; J. Chem. Phys. 1971, $54,724$.

42. Hückel, E.; Z. Phys. 1931, 70, 204.

43. Roothaan, C. C. J.; Rev. Mod. Phys. 1960, 32, 179.

Submitted: September 16, 2018

Published online: January 9, 2019 